\title{
DESLANDES, Suely Ferreira; CONSTANTINO, Patrícia (Orgs.). 2018. Exploração sexual de crianças e adolescentes: interpretações plurais e modos de enfrentamento
}

Natalia Farias Silva e Laura Nogueira de Assis

\section{(2) OpenEdition}

\section{Journals}

Edição electrónica

URL: https://journals.openedition.org/aa/5005

DOI: 10.4000/aa.5005

ISSN: 2357-738X

\section{Editora}

Programa de Pós-Graduação em Antropologia Social (UnB)

Edição impressa

Paginação: 312-316

ISSN: 0102-4302

\section{Refêrencia eletrónica}

Natalia Farias Silva e Laura Nogueira de Assis, «DESLANDES, Suely Ferreira; CONSTANTINO, Patrícia (Orgs.). 2018. Exploração sexual de crianças e adolescentes: interpretações plurais e modos de enfrentamento», Anuário Antropológico [Online], v.45 n. 1 | 2020, posto online no dia 27 janeiro 2020, consultado o 22 julho 2022. URL: http://journals.openedition.org/aa/5005 ; DOI: https://doi.org/ 10.4000/aa. 5005

\section{(c) (i) () $\Theta$}

Creative Commons - Atribuição-NãoComercial-SemDerivações 4.0 Internacional - CC BY-NC-ND 4.0 https://creativecommons.org/licenses/by-nc-nd/4.0/ 


\section{DESLANDES, Suely Ferreira; CONSTANTINO, Patrícia (Orgs.). 2018. Exploração sexual de crianças e adolescentes: interpretações plurais e modos de enfrentamento. São Paulo: Hucitec, 414p.}

\begin{abstract}
Natalia Farias Silva • Universidade de São Paulo - Brasil
Graduanda em Enfermagem na Escola de Enfermagem da USP e foi bolsista PUB de Iniciação Científica, entre 2018 e 2019, com o projeto "Exploração sexual de crianças e adolescentes e alteridade geográfica: análise interseccional da construção narrativa de agenciamentos, condições sociais de saúde e direitos". Tem grande interesse de pesquisa pelas áreas de saúde coletiva, antropologia, violência, sexualidade e gênero.
\end{abstract}

\section{Laura Nogueira de Assis • Universidade de São Paulo - Brasil}

Graduanda em Nutrição na Faculdade de Saúde Pública da USP, foi bolsista do projeto de iniciação científica "Gênero, sexualidade, saúde e violência na Amazônia: o caso da exploração sexual de meninas indígenas" do Programa Unificado de Bolsas entre agosto de 2018 e agosto de 2019, declinando-se sobre o estudo de antropologia e marcadores sociais da diferença em saúde. 
Envolta por uma polissemia de denominações, diversas moralidades e deslizamentos conceituais, a Exploração Sexual Comercial de Crianças e Adolescentes (Escca) é reconhecida em âmbito mundial a partir da Declaração Universal dos Direitos da Criança - ONU em 1959, e pela reafirmação em 1989 na Convenção dos Direitos da Criança (CDC) como "categoria jurídica" e das "violações de direitos" (Lowenkron, 2008). No Brasil, apesar de existir uma vasta e sólida produção de diversas áreas do conhecimento sobre prostituição, mercados do sexo e tráfico de pessoas, a produção acadêmica sobre "exploração sexual" é menor e apresenta uma diversidade teórico-metodológica mais restrita.

Com a finalidade de conceber um material de referência que contribuísse tanto na conceituação do problema quanto na exposição da diversidade de experiências teóricas e práticas das políticas de enfrentamento à Escca em contextos variados no Brasil, Deslandes e Constantino reúnem no livro Exploração sexual de crianças e adolescentes: interpretações plurais e modos de enfrentamento trabalhos de distintas filiações disciplinares - como antropologia, serviço social, direito, enfermagem, psicologia, entre outras. $\mathrm{O}$ arranjo da obra (dividida em "Parte I Problematizando o Fenômeno: uma visada das Ciências Sociais" e "Parte II - A Exploração Sexual de Crianças e Adolescentes nos territórios e perspectivas de enfrentamento") propõe dois desafios muito relevantes no campo da saúde coletiva: admitir a presença não acessória e internamente diversificada das ciências sociais e construir um diálogo entre as duas perspectivas do problema previstas pelas organizadoras - a problematização teórica e o enfrentamento prático da

Escca. Nessa lógica, o leitor é conduzido a uma análise da produção de conhecimento e à sua relação na implementação de políticas públicas para o problema.

Na introdução, Deslandes e Constantino refletem sobre a Escca como categoria heurística e de ação, apresentam as agências nacionais e internacionais relacionadas e as normativas legais. Expõem a dificuldade de se conceituar o campo da "exploração sexual" pontuando a confusão entre termos como "pedofilia", "assédio" e "abuso sexual", além de entenderem que a divisão da temática pelas modalidades: "prostituição", "pornografia", "turismo para fins sexuais" e "tráfico de pessoas", pode implicar omissões e ações nocivas para o enfrentamento da Escca.

Na parte I do livro, a discussão a respeito do consentimento do adolescente nas práticas do comércio sexual é abordada nos dois primeiros capítulos. No primeiro capítulo, Olivar tece a relação das políticas vigentes no campo da prostituição adulta com as normativas para Escca e compreende essa última principalmente como um dispositivo de governamentalidade de determinadas relações, sexualidades e corpos. De modo a expor os efeitos na vida dos adolescentes, desvela os discursos dos que compõem o sistema administrativo da Escca e sugere que, atrelados a uma superioridade moral e a um sistema de assimetrias, distanciam-se cada vez mais das possibilidades de enfrentamento do problema. Já no segundo capítulo, Nascimento e Fonseca focam a abordagem nas dinâmicas de gênero com a atuação na Escca por meninos e travestis menores de idade. Deixam evidente como é construída a lógica de gênero no mercado sexual, dadas as concepções sociais que entendem como machistas e heteronormativas, e correlacionam essa 
análise à efetividade das políticas públicas de enfrentamento da Escca para esses grupos de adolescentes.

Nos capítulos três e quatro, as autoras trazem uma importante reflexão para os pânicos morais e sexuais em torno da sexualidade de crianças. Ao discutir sobre o assédio sexual com base em filmes e casos jurídicos reais no terceiro capítulo, Landini e Zeytounlian produzem uma narrativa envolvente e diferenciada na coletânea. Destacam a onipresença do ambiente digital na atualidade e discorrem sobre sua relação com o grooming/luring/abuso sexual, assédio e exploração sexual on-line de crianças, que não está restrita à pedofilia. Lowenkron, no quarto capítulo, analisa densamente a CPI da Pedofilia de 2008 com o objetivo de problematizar os efeitos do fenômeno na posição de pânico moral, propondo que existe um efeito performativo expressado pelo público quando em face ao tema. Além de um desvio na agenda política brasileira, para a autora, tal CPI representou a criação de um pânico moral nacional que produziu a sensação de um perigo difuso sob a ação de um inimigo sorrateiro. Finaliza expondo que a Comissão teve holofotes apenas para o crime de veiculação de imagens pornográficas, promovendo uma sistemática anulação das vítimas.

A segunda parte da coletânea está dedicada às ações práticas de enfrentamento à Escca no país. Coimbra e colaboradores, no capítulo cinco, lançam algumas críticas às atuais abordagens de enfrentamento do fenômeno e expõem dois casos de intervenção. Neles são destacados pontos que as autoras consideram como exemplares para as possibilidades de enfrentamento: a importância de um protocolo de fluxo intersetorial para o encaminhamento dos jovens envolvidos, e a articulação dos setores público e privado para a conscientização de grupos de risco, que é mais detalhada no capítulo seis.

No capítulo sete, Teresi utiliza como recurso bibliográfico a "Pesquisa sobre Tráfico de Mulheres, Crianças e Adolescentes para fins de Exploração Sexual no Brasil" (PESTRAF), o que evidencia um paradoxo na lógica do livro. Embora tenha sido massivamente divulgada como referência para a consulta pública de números e informações sobre o tráfico de brasileiras para fins de exploração sexual, segundo análises antropológicas têm evidenciado, essa pesquisa é marcada pela notável fragilidade na construção de suas metodologias e conclusões, e pela sua capacidade de gerar pânico moral sobre o tema (Blanchette; Silva, 2014).

O oitavo, nono e décimo capítulos assemelham-se na abordagem de aparentes singularidades de territórios específicos: regiões de fronteira, no Amazonas, e a cidade turística de Fortaleza, no Ceará. As autoras expõem que a multiplicidade cultural, as limitações geográficas, as relações de poder machistas e patriarcais e, especialmente, a exploração sexual por parte de figuras de poder, são elementos que transcendem a situação de vulnerabilidade socioeconômica dessas regiões. Destacam ainda a importância das audiências abertas e encontros regionais para a elaboração de planos de enfrentamento locais realizadas no Amazonas, e iniciativas desenvolvidas com acolhimento multidisciplinar através de campanhas in loco de sensibilização, conscientização e identificação dos envolvidos no mercado da exploração sexual, no Ceará. 
Como encerramento do livro, Deslandes, Campos e Constantino analisam um estudo diagnóstico no qual são apresentados dados sobre a incidência de Escca e reflexões sobre seu enfrentamento em três das cidades mais ricas do país, situadas na região petrolífera do Rio de Janeiro. A pesquisa denota a invisibilidade da problemática por diferentes grupos da cidade e demonstra, na forma de indicadores, a fragilidade das políticas de enfrentamento da rede de atendimento dessa região. O capítulo e a obra finalizam com a exposição da complexidade do enfrentamento da Escca no Brasil em variados contextos, os quais não se limitam a baixas condições socioeconômicas.

No livro há um diálogo constante nas produções de conhecimento, com algumas referências citadas em repetidas ocasiões, denotando relativa sinergia entre os autores. Tal sinergia revela, paradoxalmente, uma condição interessante do campo: a consistência das cisões e das indefinições (Olivar, 2016). No livro é possível evidenciar momentos marcados por verdadeiras divergências no plano da construção social e política da verdade, em que valores de uma causa moral que é superior a qualquer evidência empírica são reafirmados. De alguma forma, tais momentos representam os limites e as possibilidades do que é proposto pelas organizadoras do livro: construir um diálogo produtivo entre campos identificados como "acadêmico" e como "de intervenção".

Ao reunir conceituações, concepções, reflexões e análises de diferentes vertentes acadêmicas e ideológicas sobre o tema da exploração sexual comercial de crianças e adolescentes no Brasil, essa coletânea é capaz de expor as principais e atuais formulações teóricas sobre o fenômeno e as implementações práticas brasileiras. Tal proposta já é relevante por si só, à medida que faz um caminho inverso e aplica na teoria de um livro o que o enfrentamento prático para Escca preconiza: ações articuladas de forma intersetorial e multiprofissional. $\mathrm{O}$ trabalho pode ser situado como uma referência indispensável tanto aos pesquisadores e profissionais da rede de enfrentamento como aos leitores leigos, pois une em um único documento a exposição de marcos e normativas históricas e atuais sobre o tema, com descrições e críticas sobre diversas medidas práticas já aplicadas abrangendo também as singularidades da temática em regiões descentralizadas.

Resulta relevante na leitura desse livro a presença das abordagens antropológicas e sua relação de clara tensão com o "campo de enfrentamento". Tais abordagens trazem para o livro realidades empíricas diversas e múltiplas vozes de agentes envolvidos, para além das visões hegemônicas: desde adolescentes diversos com pontos de vista também variáveis em relação a prática no mercado sexual, até os posicionamentos de agentes do Estado e de organizações não governamentais em múltiplos planos e níveis. Além disso, como resultado de pesquisas etnográficas, oferecem perspectivas teóricas novas para compreender a "exploração sexual". 


\section{Referências bibliográficas}

BLANCHETTE, T. G.; SILVA, A. P. 2014. "As rotas da PESTRAF: empreendedorismo moral e a invenção do tráfico de pessoas no Brasil”. Revista Ártemis, n. 18, p. 12-27.

LOWENKRON L. Sexualidade e (menor)idade: estratégias de controle social em diferentes escalas. Dissertação de Mestrado, PPGAS, Museu Nacional, UFRJ, Rio de Janeiro, 2008.

OLIVAR, J. M. "[...] o que eu quero para minha filha": rumos de (in)definição da exploração sexual no Brasil . Mana, v. 22, n. 2, p. 435-468, 2016. 